NBER WORKING PAPER SERIES

\title{
INVENTORIES IN THE KEYNESIAN \\ MACRO MODEL
}

Alan S. Blinder

Working Paper No. 460

NATIONAL BUREAU OF ECONOMIC RESEARCH

1050 Massachusetts Avenue

Cambridge MA 02138.

February 1980

I have benefited from the helpful comments of Costas Azariadis, William Branson, Jonathan Eaton, Ray Fair, Stanley Fischer, Robert Gordon, Herschel Grossman, Dwight Jaffee, Louis Maccini, Dennis Snower, Robert Solow, Yoram Weiss, and an anonymous referee on earlier drafts. Financial support from the National Science Foundation and the Institute for Advanced Studies, Jerusalem, is sratefully acknowledged. The research reported here is part of the NBER's research program in Economic Fluctuations. Any opinions expressed are those of the author and not those of the National Bureau of Economic Research. 
Inventories in the Keynesian Macro Model

\section{ABSTRACT}

An otherwise conventional Keynesian macro model is modified to include inventories of final goods by (1) drawing a distinction between production and final sales, and (2) allowing for a negative effect of the level of inventories on production. Two models are presented: one in which the labor market clears and one in which it does not. Both models are stable only if the negative effect of inventories on production is "large enough." Both mo 3 els also imply that real wages move countercyclically - in direct contrast to the usual implication of Keynesian models. Detailed analysis of the marketclearing model show that there should be negative correlation between the levels of inventories and output, and between changes in inventories and changes in output, over the business cycle. However, inventory change should be positively correlated with the level of output.

Alan S. B1inder Department of Economics Princeton University Princet on, N. J. 08544 (609) $452-4010$ 
I.-_Motivation and Relation to other Literature

If a man from Mars visited this planet and spent a year or so reading all the macroeconomic literature of the past 15-20 years, he would not come away feeling that inventories are of much importance. If we then gave him five minutes with the National Income and Product Accounts of the United States, he would quickly conclude that there was something lacking in his education. Inventories are important. Indeed, as a rough generalization, changes in the rate of real inventory investment have accounted for approx-

- imately 70 percent of the decline in real GNP during a typical postwar recession (see Table 1 ). It would seem likely, therefore, that inventories play a crucial role in the propagation of business cycles.

If our Martian read some of our leading elementary textbooks, he would again find a prominent role assigned to inventories as the principal force driving national income to its "equilibrium" level-the level at which there is no undesired inventory accumulation or decumulation. $l$ But if he tried to pursue this Iine of reasoning in the more advanced textbooks, he would find littie more.? And if he sought after discussions of inventories in the theoretical literature, he would come up nearly empty-handed. 3 Inventories, in a word, have been neglected by macroeconomic theorists.

In the period immediately following the publication of The General Theory, there was a flurry of theoretical work on inventories, culminating in METZLER's (1941) classic paper. Working with the simplest possible difference equation system, METZLER pointed out that inventory investment could conceivably destabilize an otherwise stable system. This paper extends METzLER's line of reasoning by showing that, in a modern Keynesian model, including inventories:

(a) a well-known condition for stability of a monetary economy due to CAGAN (1956) becomes stricter on account of inventories;

(b) inventories add an additional stability condition to the model--a condition that is not innocuous since it could be violated under plausible parameter values. 
Table 1

CHANGES IN GNP AND IN INVENTORY INVESTMENT

IN THE POSTWAR RECESSIONS

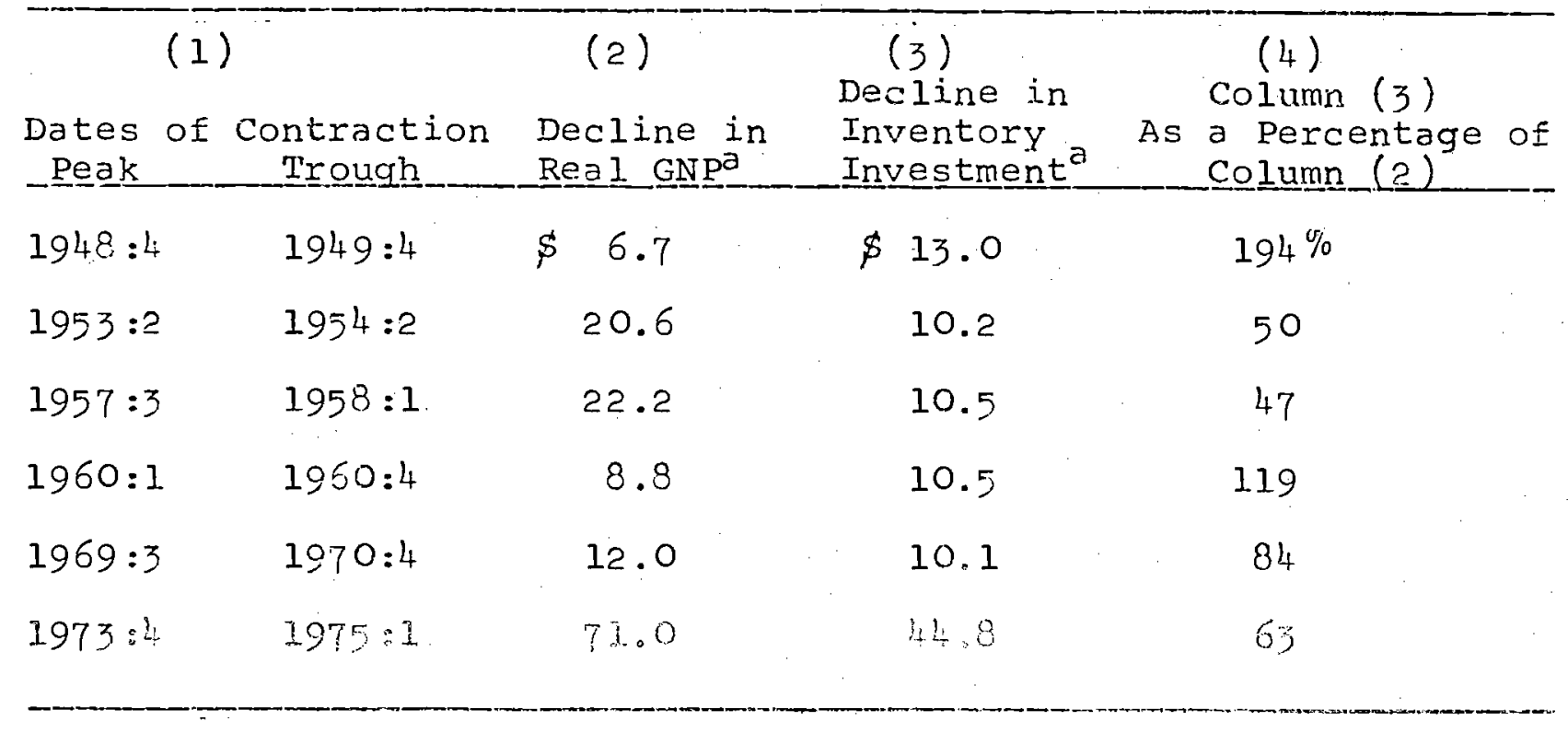

an bilitions of 1972 dollars.

Source: The National Income and Product Accounts of the United States, 1929-74, and Survey of Current Business. 
But while METZLER stressed the destabilizing role of inventories, many other authors have stressed their stabilizing role. Obviously, . inventories of finished goods give firms flexibility either to meet abnormally high demand by selling more than they produce, or to cope with abnormally low demand by producing more than they sell. Thus production and employment can be stabilized relative to demand when output is storable. It seems particularly important to recal.J. this role of inventories in light of the recent work on "spiliovers" by BARRO and GROSSMAN (1971, 1976) and others.

One of the bases of the BARRO-GROSSMAN analysis is that, when sticky wages and prices prevent the attainment of the full walrasian general equilibrium in the short run, the actually quantity transacted in a market normally will be the minimum of supply and demand. This so called "min condition" is based on the principle of voluntary exchange, but retains its plausibility only if output. is non-storable." Consider, for examole, the BAFRO-GROSSMAN generalized excess supply scenarjo. If firms cannot sell all the output they would like to, they react by reducing production and firing workers. In this way, excess supply in the goods narket "spills cver" into the labor market as well. But what if output is storable at moderate costs? It seems unlikely, under these circumstances, that production cutbacks and layoffs would be a rational reaction to moderate short-run gluts in the product market. Instead, firms can--and apparently do--maintain production and store their excess output for subsequent sale. Only if poor sales. performance persist for some time, or are extremely large, do firms reduce their work forces. In this way, inventories jimit the spillover of excess supply from the product market to the labos markets to instances of extreme drops in demand.

Or consider the BARRO-GROSSMAN scenario of generalized excess demand. In this case, workers who are unable to purchase the commodities they desire (because these commodities are in excess demand) react by reducing their supply of labor. Why work when (at the margin) there are no goods to buy? Thus excess demand in the goods market spills over into the labor market. But once again, barring generalized stock-outs, this will not happen in an economy 
in which there are inventories of goods. There may well be a flow excess demand for goods; but, at least for a while, firms can meet this excess demand out of inventories. Thus it seems unlikely that excess demand for goods would lead to a drop in labor supply, except in extreme circumstances. 5 It is worth pointing out that this particular spillover mechanism accounts for what may be the most empirically distressing implication of the mARRO-GROSSMAN model: that positive shocks to aggregate comodity demand, starting from a position of equilibrium, will reduse real output.

The model considered here is very different from the BARROGROSSMAIN model, though at least one of its basjc aims is identical: to explain the link between aggregate demand and real output. For example, the "min condition" for the goods market does not appear here because it makes little sense in the presence of inventories. Instead, I assume that consumers always purchase their quantity demanded. Stockouts at the aggregate level are ignoced. When there is excess supply, firms add the excess to their inventories ano

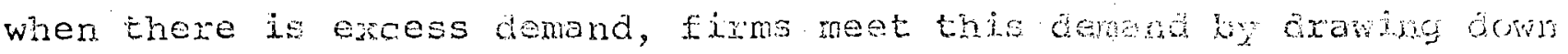
inventories. In either case, the resulting inventary imbalance induces firms to adjust their production and emplognent decisions: but the adjustments are gradual, so the sharp cornexs of DARRO and GROSSMAN are smoothed out. 6

Finally, since the model proposed here offers an litexative way to forge the link between aggregate demand and real output, mention should be made of the currently most popular vay of doing so. In standard Keynesian analysis, money wages are assumed fixed in the short run, so higher prices (caused by figher aggregate demand) encourage employment: and output by lowering rea beses. ' $B_{X}$ contrast, in the main model presented here, money wages nove promptiy to clear the labor market, and real wages actually move procycljcaIly. I make the assumption that money wages are fully flexible not for its empirical validity, but to illustrate thet irvertoriso provide a link between demand and production that does not rely on wage rigidities. Later in the paper, the assumption of inctintiy flexible wages is replaced by an expectations-augner.ed philips 
curve and a "min condition" for the labor market. It is shown that the analysis, while greatly complicated, is not altered in any essential way by these changes. In particular, the conclusion that wages move procyclically is maintained.

The plan of the paper is as follows. The next section offers a general discussion of the motives for holding inventories, noting how each motive bears on the specification of macro models. Then, choosing one particular rationale for inventories, I clevelop and analyze in section III a complete macro model in which all markets "clear." Section IV discusses the modifications required when the labor market does not clear, and sketches how the analys is is affected. Section $V$ offers some brief concluding remarks.

\section{The Specification of Inventory Behavior}

Where should inventories be brought into conventional macroeconomic models? The answex depends on whether inventories are inputs or outputs, and on why firms hold them; but a wide variety of micro models suggest that higher wyerory stocks lead to lower current output.

Among the major motives for holding inventories that appear in the literature is improved production scheduling (see, for example, HOLT, MODIGLIANI, MUTH and SIMON (1950)). The idea is that multiproduct firms can operate more efficiently if inventories give then flexibility in scheduling production runs. So this suggests that the stock of inventories, $N$, should enter the production function as another factor of production in addition to employment, $E: Y=f(E, N), f_{N}>0$. In a model. like this, inventories could either be inputs (i.e., raw matexials and intermediate goods) or outputs (i.e., finished goods). The crucial question is whether and how in affects the marginal productivity of labor. The basic rationale seems to suggest that inventories raise labor's productivity; and, if so, this would stimulate employment demand. But it should also be true that, when the stock of inventories rises, the incentive to raise it further by producing diminishes (as long as there are diminishing returns to inventories). Thus, both the costs (via higher productivity) and the benefits of production are reduced by 
rising $\mathrm{N}$, with consequently ambiguous effects on output.

other models of inventory behavior seem less ambiguous regarding the effect of inventories on production. For example, it is commonly hypothesized that firms hold inventories as a buffer stock in the face of fluctuating demand (see, for example, MILLs (1962)). In that case, inventories are probably outputs which do not directly effect the production function. Instead higher $N$ reduces the probability of having a stock-out. Given diminishing returns to inventory-holding, this presumably leads to lower production.

A closely related motive for holding inventories is speculation on future price movements. Indeed, this is almost indistinguishable from the buffer stoak motive in that expectations of high future prices relative to costs (the speculative motive) and large future sales (the buffer-stock motive) amount to more or less the same thing.

While these last two motives amount to using inventories to smooth production relative to demand, some firms may wish to do just the opposite: to bundh production relative to seiss. Ihis could happen where dramatically increasing returns to scale dictate that production be done in large "production runs," which are then put into inventory and gradually sold. In this production run model, it seems fairly clear that excessively high inventories will induce a postponement of the next production $r u n$, and hence a reduction in "average" output and employment over an interval of time.

Still another motive for holding output inventories, suggested by MACCINI (1977) among others, is that high inventory stocks may stimulate a single firm's demand by reducing delivery lags. In this case, it seems appropriate to omit $N$ from the production function, but include it in the firm's demand function. But it is not clear that $\mathrm{N}$ should have a similar stimulative effect on aggregate demand.

others have suggested that input inventories are held in order. to economize on purchasjng costs. This could be either because there 
is a fixed cost to purchasing inputs-the assumption that underlies "optimal lot.size" models, or because firms face a rising supply price of inputs which makes it economical to smooth input purchases relative to input usage. 8 In such a case, the rate at which inventories are used should appear in the production function, while the rate at which they are purchased should depend on the existing stock.

What effects, then, should inventories have on aggregate denand? Presumably, all the models agree that desired inventory investment should be a decreasing function of $N$. But there is no persuasive reason to think that $N$ has any direct effects on the other components of aggregate demand--what are called Einal sales.

What about aggregate supply? Consiciering first output inventories, the production-scheduling motive suggests that $\partial y / \partial \mathrm{N}$ might conceivably be positive. But the other motives seem strongly to suggest the opposite: the higher the level of inventory stocks, the less the firm will be inclined to produce. One would also expect high inventories to lead to price cuts.

But input inventories would have different etfects. Mugine ai firm whose inputs are storable, but whose outputs are not. If it finds itself with too many inventories, it will have an incentive to raise production (and employment) anā cut prices. If it can store both inputs and outputs, the implication for production decisions becomes unclear. It depends on the relative costs and benefits of inventorying inputs versus outputs.

Finally, the nature of inventories has implications for the accounting identity governing inventory accumulation or decumulation, $\dot{N}$ : For example, if inventories are outputs, then $\dot{N}$ is the difference between production and sales, so a xise in production (other things equal) raises $\dot{N}$. But if inventories are inputs, then $\dot{N}$ is the difference between input purchases and input usage, which will fall when production rises.

The macroeconomic model presented here is based on a very specific micro model of inventory behavior which $I$ have presented in another paper (BLINDER (1.973)). The model is one of ouiput 
inventories held for reasons of anticipated price appreciation or, what amounts to the same thing, as a buffer stock held because of anticipated fluctuations in demand. As I show in that paper, the level of inventories affects employment demand (and hence output) negatively:

$$
E^{d}=E^{d}(w, N) E_{w}^{d}, E_{N}^{d}<0
$$

This function has the property that $E^{d}\left(w, N^{*}\right)$, where $N^{*}$ is the desired or optimal level of inventories and $w$ is the real wage, is equal to the inverse of the marginal productivity schedule:

- $f^{-1}(w)$. For higher inventories, the labor demand schedule lies below the marginal productivity schedule; and for lower inventories, it lies above.

While I have derived it in a very specific context, let me try to explain why I believe that such a labor demand function would arise under quite general circumstances. Consider any of a family of models where the firm maximizes the discounted present value of its profits subject to (among other things) a constraint thet inventory change equals production minus sales:

$$
\dot{N}=f(E, \ldots)-x .
$$

Any of a variety of variables could enter $f(\cdot)$ without affecting the argument; similarly, sales or price could be endogenous or exogenous for present purposes. The Hamiltonian for such a problem would look like this:

$$
H(E, \ldots)=\text { sales revenues }-w E \text { - other costs }+\lambda[f(E, \ldots)-x] \text {, }
$$

where again I need not specify the nature of sales revenues or non-wage costs. Here $\lambda$ is the shadow value of inventopies, and a well-known result of optimal control theory is that:

$$
\frac{\partial \mathrm{J}}{\partial \mathrm{N}_{\mathrm{O}}}=\lambda_{\mathrm{O}}
$$

where $J$ is maximized (with respect to $E$ and other variables) profits, and $\mathbb{N}_{O}$ is the initial stock of inventories.

The first order condition for optimal employment is $f_{E}(E, \ldots)=w / \lambda$ at every instant, which has two important implications:

(a) in making productetion (as opposed to sales) decisions, the firm compares its costs with $\lambda$, not with the market price. 
This is because it is deciding whether to turn inputs into inventories. Then, in deciding whether to sell out of inventories, it will compare $\lambda$ with the market price. 9

(b) optimal $\mathrm{E}$ is a decreasing function of $\mathrm{w}$ and an increasing function of $\lambda$. But this means that we can derive the abovementioned labor demand function by showing that $\lambda_{0}$ is a decreasing function of $\mathrm{N}_{\mathrm{O}}$. Now note that:

$$
\frac{\partial \lambda}{\partial N_{O}}=\frac{\partial^{2} \frac{J}{\partial}}{\partial N_{O}^{2}},
$$

and that $\partial^{2} \mathrm{~J} / \partial \mathrm{N}_{0}^{2}$ must be negative in a wide variety of problems. (This is just a statement of diminishing returns, and is, in fact, a sufficient condition for a maximizing program to exist.)

While the labor demand-function used here is therefore quite general, note that the production-scheduling model raises the possibility that $\partial y / \partial \mathrm{y}>0$. It should come as no surprise that models with otuput inventories normally will he stable ondy if a rise in $N$ reauces $N=Y-x$, where $x$ is finaj sales. Thus the stability of the model hinges precariously on the effects of inventories on production decisions--a question that cannot be answered by microeconomic theory, and that has barely been investigated in empirical macroeconomics. 10

\section{A Macroeconomic Model with Inventories}

\subsection{Specification of the Model}

The demand side of the model is quite standara, except that recognition of inventories requires that a distinction be drawn between output and final sales. Inus, instead of an is curve, the following expression describes real final demand:

$$
x=c(y-t(y), x)+g \text {, }
$$

where $y$ is GNP (or national income), $t(y)$ is real taxes, $r$ is the real interest rate, $c$ is real private demand, and $g$ is real goverment demand. The capital stock is ignored on the grounds that it can be treated (roughly) as constant. Since the period of time that I am concerned with is quite short, this seems more legitimate 
than it is in many other contexts.

The demand side is completed by an LM curve based on the strict transactionist view of the demand for money: 11

$$
M / P=L(r+\pi, Y)
$$

where $M$ is the nominal money stock, $P$ is the price level, and $\pi$ is the expected rate of inflation. Making the distinction between $x$ and $y$ raises interesting questions about which is the appropriate transaction variable in the denand function for money. But since this is not the subject of this paper I sweep these issues under the rug and adopt the conventional variable: gross national product. Notice that (2) embodies the assumption that $r$ adjusts instantly to maintain money-market equilibrium, but (1) implies no such assumption about the goods market. When inventories are changing $(x \neq y)$, the system is off the Is curve, which is

$$
y=c(y-t(y), r)+g \text {. }
$$

What I call an aggreqate demand curve can be derived from (1) and (2). First invert (2) to obiains

$$
r=R(y, m)=\pi R_{y}=-\frac{I_{y}}{L_{r}}>0, \quad R_{m}=\frac{I}{I_{r}}<0,
$$

where $\mathrm{m}=\mathrm{M} / \mathrm{P}$ is the real money stock. Then substitute (3) into (1) to obtain:

$$
x=c(y-t(y), R(y, m)-\pi)+g \text {. }
$$

This can be written:

$$
x=D(y ; m, \pi, g) \text {, }
$$

where the function $D(\cdot)$ has the following derivatives:

$$
\begin{aligned}
& D_{y}=c_{y}\left(1-t^{\prime}\right)+c_{r} R_{y} \\
& D_{m}=c_{r} R_{r}>0 \\
& D_{\pi}=-c_{r}>0 \\
& D_{g}=1
\end{aligned}
$$

The conventional assumption in IS-HR analysis that $D_{y}$ is a positive number less than unity will be reflectod in what follows. Aggregate demand is identified with sales by anuing that generalized stodkouts do not occur. 
The supply side of the model consists of an equation that says that the labor market clears given the (possibly disequilibrium) state of inventories:

$$
E^{d}(w, N)=E^{s}(w), E_{w}^{s} \geq 0
$$

and a production function: 12

$$
y=E\left(E^{S}(w)\right) \text {. }
$$

These two equations are solved very simply for an agqregate supply function:

$$
\begin{aligned}
& Y=Y(N), \\
& Y_{N} \equiv f^{\prime}(E) E_{N}^{d} \frac{E_{w}^{s}}{E_{W}^{s}-E_{w}^{d}}<0 .
\end{aligned}
$$

Given predetermined values for the three state variables: $N, m$, and $\pi$, equations ( 4 ) and ( 7 ) determine the values of $x$ and $y$ for any given $g$. Figure 1 depicts one such solution on a standard "Keynesian cross" diagram. Equation ( 7 ) already tells us how $y$ depends on the state variables. To obtain a similar solution function for $x$; substitute (7) into (4) to get

$$
\mathrm{x}=\mathrm{X}(\mathrm{N}, \mathrm{m}, \pi ; \mathrm{g})
$$

where:

$$
\begin{aligned}
& x_{N}=D_{Y} Y_{N}<0 \\
& x_{z}=D_{z}, z=m, \pi, g .
\end{aligned}
$$

Thus, initially monetary or fiscal policy effects $x$ but not $Y$. The position of the economy defined by (?) and (8) will not in general be an equilibrium because one or more of the state variables will change. Changes in the stock of inventories are governed by a straightforward accounting identity:

$$
\dot{N}=\mathrm{Y}-\mathrm{X} \text {. }
$$

Changes in the expected rate of inflation are assumed to be adaptive: 13

$$
\dot{\pi}=\beta(\dot{P} / \mathrm{P}-\pi) \quad \beta>0 \text {. }
$$

Finally, since I assume that budget deficits are bond-financed, changes in real balances happen either (a) abruptly due to an openmarket operation or (b) smoothly due to changes in the price level. Thus, except at instants when there are open-market operations,

$$
\dot{m}=-m(\dot{P} / \mathrm{p}) \text {. }
$$

This requires an equation for price dynamics, for which the following seems suitable: 


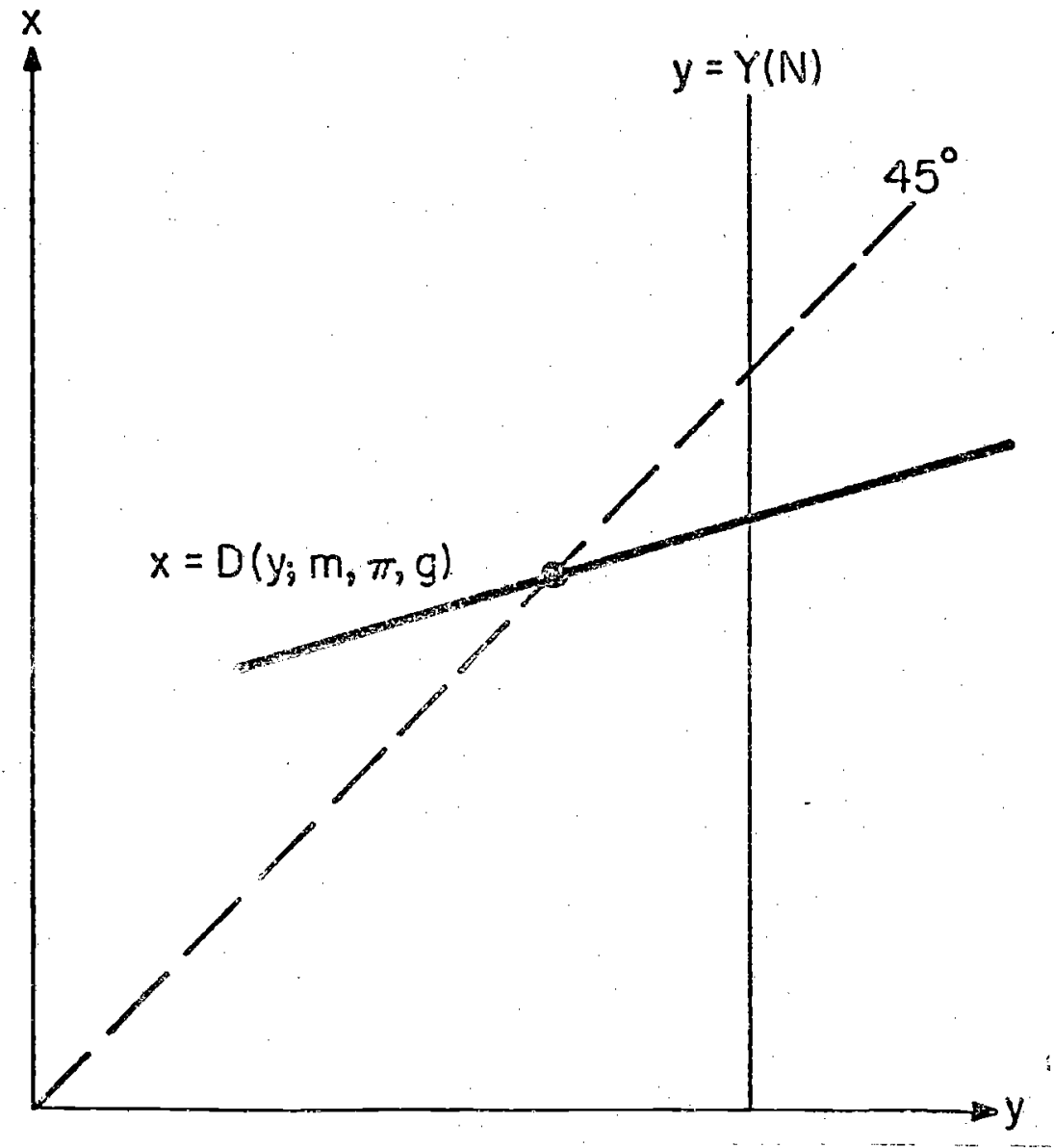

Figure 1 


$$
\dot{P} / \mathrm{P}=\pi+\theta\left(N^{*}-N\right), \theta>0,
$$

where $N^{*}$ is the specific (optimal) level of inventories that makes $\mathrm{E}^{\mathrm{d}}\left(\mathrm{w}, \mathrm{N}^{*}\right)$ coincide with the marginal productivity schedule. In general, as shown in BLINDER (1978), $\mathrm{N} *$ would depend on the production function, the nature of inventory holding costs, the entire future path of expected prices (and sales constraints, if there are any), and the real rate of interest. However, I ignore all this and treat $N^{*}$ as a constant in the short run. ${ }^{14}$ Equation (11) has empirical support in that unfilled orders are the typical indicator of excess demand in product markets in recent empirical price equations (see, for example, GORDON (1975)). And for firms that produce to order, unfilled orders play the same role as inventories play for firms that produce to stock. Indeed, unfilled orders can be viewed usefully as negative inventories (see MACCINI (1976)). From (11), the equation for changes in the real money supply follows immediately. Except at moments of oper-market operations:

$$
\dot{\mathrm{m}}=\cdots \pi-\min (\mathrm{m}-\mathrm{i}) \text {. }
$$

Equilibrium occurs only when (9), (10) and (12) are all equal to zero. That is, when GNP equals final sales, expectations are correct, and inflation is zero. 15

2.2 Comparative Statics of Eguilibrium positions

There seem to be three interesting questions to ask about what policy variables ( $M$ or $g$ ) do to endogenous variables like; $y$ or $w$. First, what are the instantaneous effects? Second, what are the equilibrium effects? Third, what do the paths look like in the interim period? The ij.rst question has already been answered: in the fixst instant, a $x i s e$ in $g$ or $M$ increases $x$, but has no effect on either $y$ or $w$ (or on the inflation rate). I turn next to the second question.

Using (7) and (8), and imposing the requirements for equilibrium, the following equations define steady states of the model:

$$
\begin{array}{ll}
\mathrm{Y}(\mathrm{N})=\mathrm{X}(\mathrm{N}, \mathrm{m}, \pi ; g) & (\dot{\mathrm{N}}=0) \\
\dot{\mathrm{P}} / \mathrm{P}=\pi & (\dot{\pi}=0) \\
\pi \quad=\theta\left(N-N^{*}\right) & (\dot{\mathrm{m}}=0)
\end{array}
$$

But the last two, in conjunction with the price equation (11), 
require that $\pi=0$ and $N=N^{*}$ in equilibrium.

Thus the equilibrium version of the model can be represented by the standard IS curve, $\left(I^{\prime}\right)$; the LM curve with $\pi=0$ :

$$
M / P=L(r, Y) \text {; }
$$

and a classical labor market:

$$
w=f^{\prime}\left(E^{d}\right), E^{s}=E^{s}(w), E^{d}=E^{s} \text {. }
$$

In its most compact form, equilibrium is defined by the single equation:

$$
\mathrm{Y}\left(\mathrm{N}^{*}\right)=\mathrm{X}\left(\mathrm{N}^{*}, \mathrm{~m}, \mathrm{O} ; \mathrm{g}\right) \text {. }
$$

* Thus, $\mathrm{Y}^{*}=\mathrm{Y}\left(\mathrm{N}^{*}\right)$ is the "natural rate" of output, and $\mathrm{W}^{*}=\mathrm{W}^{*}\left(\mathrm{~N}^{*}\right)$ is the equilibrium real wage. Neither of them can be permanently affected by policy. Nor can $x$, since $x=y$ in equilibrium.

\subsection{Dynamic Adjustment Paths}

I turn next to the dynamic paths of the important macroeconomic variables, deferring for the moment the issue of whether the dynamic system is stable. Since. I ignore many variables that change in the long run, it is these short-run responsesmmot the steady states..m that are of greatest interest.

Figure 2 shows the model in an initial position of equilibrium at point $A$. Here $x=y$, so $N$ is unchanging; inflationary expectations are correct ana equal to zero; and real balances are constant. Now suppose there is a dose of expansionary monetary ( $a M>0)$ or fiscal ( $\mathrm{dg}>0$ ) policy, shifting the demand curve upwards from $\mathrm{D}_{\mathrm{O}}$ to $\mathrm{D}_{1}$.

Initially, the economy's position shifts upwards to B: sales are raised, but GNP is not. But at B, inventories are aisappearing. Consequently, the supply curve starts moving to the right (see equation (7)). At the same time, two effects start working on the demand curve. In a stable system, bhe more important of these is that (11) implies that inflation begins, eroding real balances, and causing the demand curve to shift downwards towards $D_{2}$. The second effect is that inflation raises inflationary expectations (by (10)), and this reduces the real interest rate (by (3)), which stimulates 


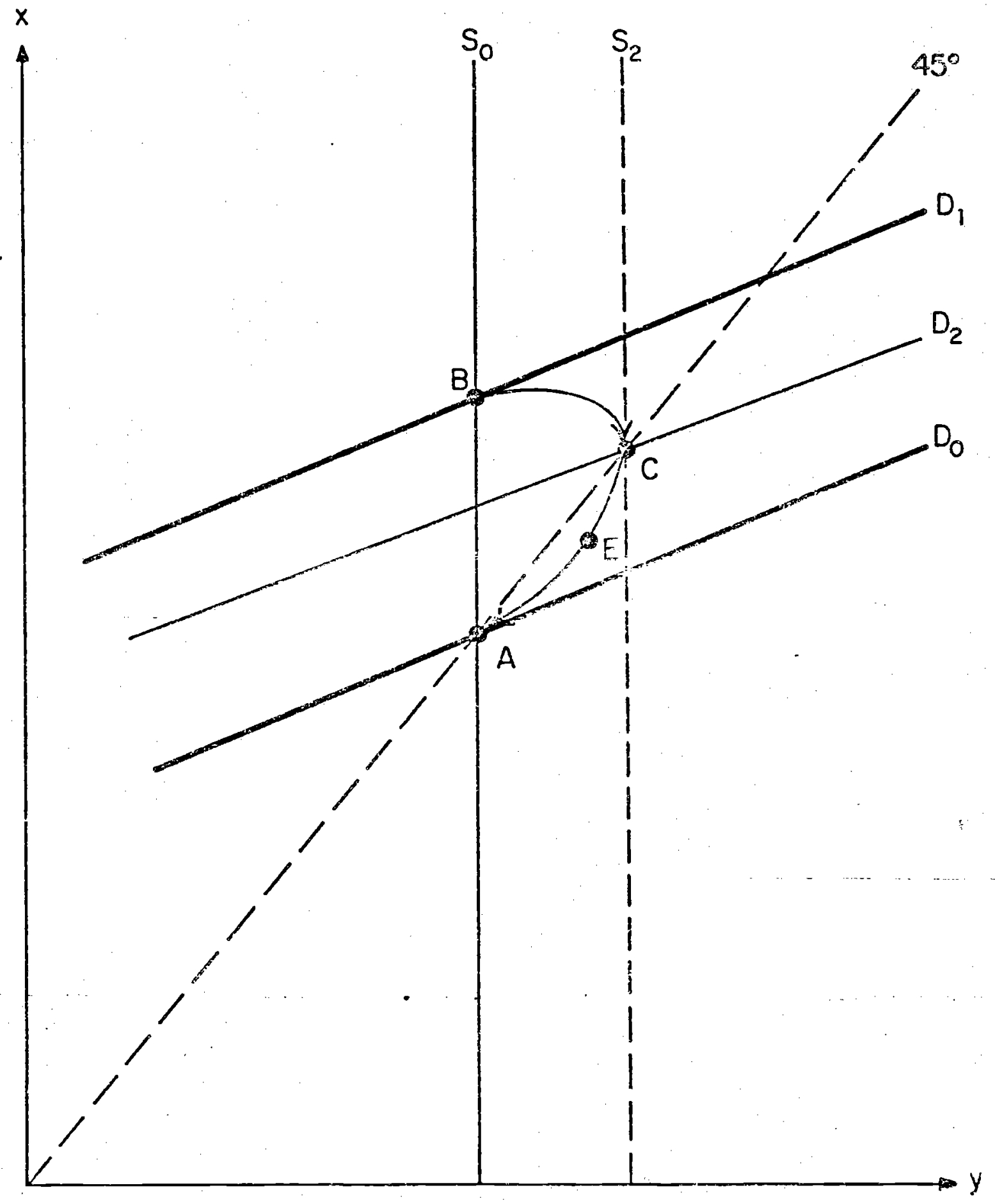

Figure 2 
spending. The diagram assumes that the former effect dominates, so that the position of the economy moves towards the south east, as indicated by the arrow emanating from point $B$.

At some point--indicated in the diagram by point C--the supply and demand curves $\left(S_{2}\right.$ and $D_{2}$ ) intersect on the $5_{5}^{\circ}$ line. At this moment, the inventory decumulation is halted, and inventories begin to be replaced. So the supply curve starts shizting back toward its original position. However, while they are rising, inventories remain low, so the impetus for inflation remains. Prices keep rising while real output falls. In fact, for a period, inflation is accelerating while output is falling. ${ }^{16}$ Whether or not tisis is to be called a phase of "stagflation" or not is a matter of terminological dispute. But it does create an interval of time during wnich changes in unemployment and changes in inflation are positively correlated--an upwards sloping "Phillips curve" if you will.

Before turning to the conditions under which this stable scenario actually obtains, let me outline some of the observable consequences of the model. Pollowing a stimulus to agrescte denand:

(1) Final sales rise quickly to a peas, in and then decline to their original level. GNP rises much more slowly to a peak, and also declines. So the composition of GNP between final. sales and inventory change varies dramatically over the cycle.

(2) Both employment and real wages follow the path of GNP, rising to a peak and then returning to their equilibrium levels. Thus, in contrast to the traditional Keynesian and search theoretic models, real wages more procyclically.

(3) The trough in the level of inventories (N) coincides with the peak in output (both occur at point $C$ in Figuxe 2 ). As Figure 3 shows, $N$ and $Y$ display negative correlation over the cycle.

(4) The peak in inventory investment (j) lags the peak in production. (In terms of Figure $2, \dot{N}$ peaks at point $E$, while $y$ peaks at point 6.$)^{18}$ As Figure 3 indicates, $\dot{N}$ and $y$ are positively correlated, while $N$ and $y$ are neqatively correlated over the cycle. 


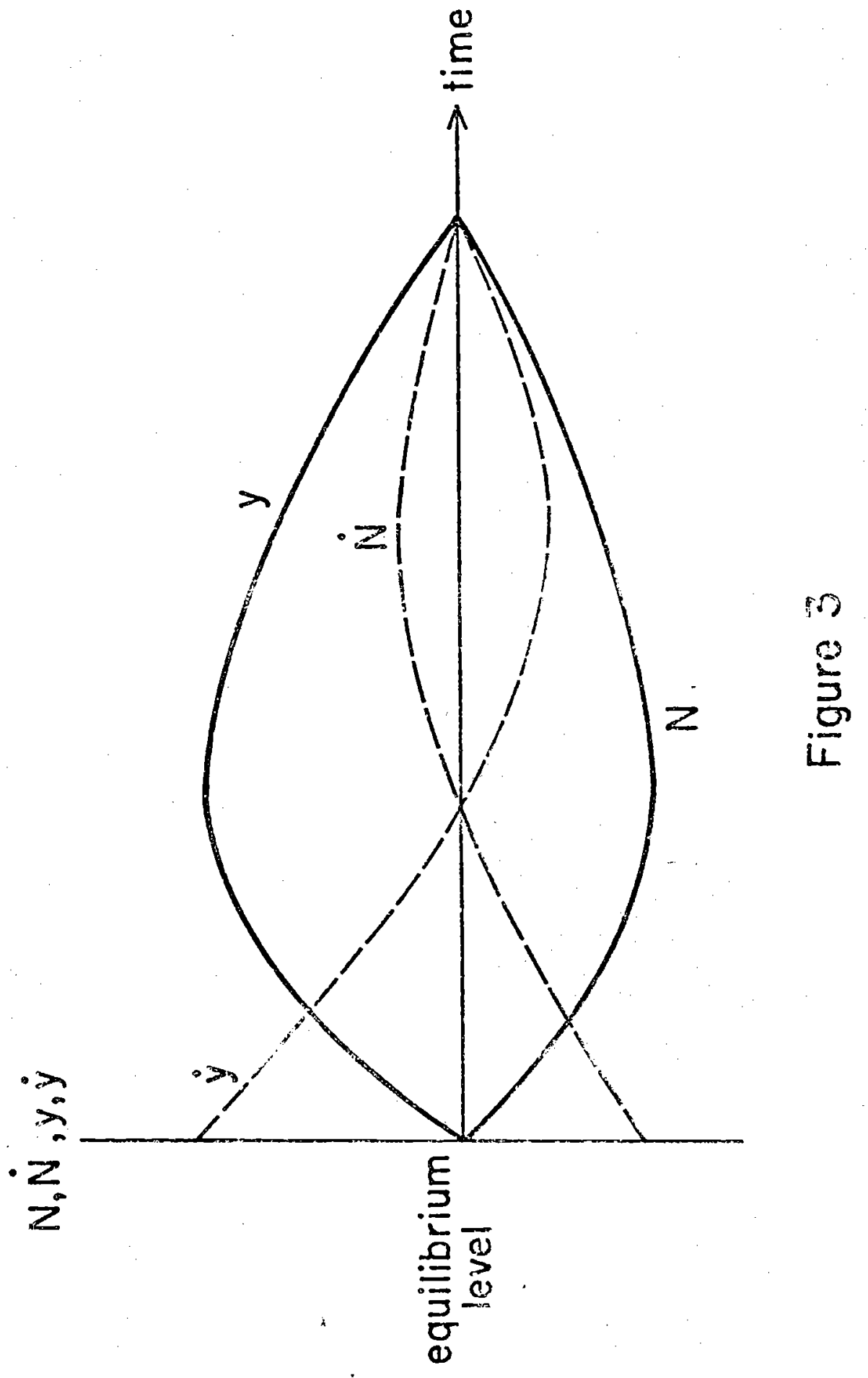


(5) Prices rise throughout the adjustment period, reaching a permanently higher level. The peak in the rate of inflation lags the peak in GNP.

2.4 4 S

The scenario just outlined is, of course, of interest only if the model is dynamicaliy stable. A formal stability analysis of this system is relegated to the $A$ ppendix, where it is shown that one of the three necessary and sufficient conditions for stability is:

$$
\therefore \quad I+\beta \frac{x_{r}}{m}>\frac{B}{x_{N}^{-Y_{N}}} .
$$

The righthand side of (14) is a positive number which is smaller (a) the slower the speed of acijustment of inflationary expectations, and (b) and the more negative is $Y_{N}-X_{N}$. The lefthand side is familiar from the work of CAGAN (1956). CAGAN found that his model (a full employment model where the "interest rate" variable in the demand for money was just $\pi$ ) woula be stable if and only if;

$$
I+\rho \frac{L_{x}}{m}>0 \text {. }
$$

Here I require instead (14), which is stronger than (11, ). 19

Notice the fundameital. role played by $\mathrm{Y}_{\mathrm{N}}$. Should $\mathrm{Y}_{\mathrm{N}}-\mathrm{X}_{\mathrm{N}}=$ $(1-D y) Y_{N}$ be zero or positive--a possibility raised by the productionscheduling model....the model is definitely unstable. Even if it is negative, the model wir. sicill be unstable unless $Y_{N}-X_{N}$ is large enough, where the precise meaning of "large enough" is spelled out in (14).

IV. A Model with a Nonechorinc Labor Market

The model presented in the last section includes two important features that $x$ an unhapoy about. First, the assumption that the labor market always clears in the short run means that the labor market adjusts to shocks wuch faster than the goods market. Second, the "Keynesian" short cun response of output to stabilization policy can occur only iff the agrengitio supply curve of labor slopes upward. Both assumptions are open io doubt, to say the least. But both can be avoided by assuming insicead that the labor market does not ciear, and instead wages aljusi: to the discrepancy between supply and demand 
for labor. In this section, I outline such a model. Since its formal analysis is quite complicated, involving four differential equations (for $\dot{N}, \dot{P}, \dot{\pi}$, and $\dot{w}$ ), interesting qualitative results are obtainable only if I suppress price expectations and assume that $\pi$ is always at its steady state value of zero.

\section{1 Specification}

I specify a nonclearing labor market in the usual way. Actual employment is determined by the principle of voluntary exchange:

$$
E=\min \left(E^{d}(w, N), E^{s}(w)\right) \text {, }
$$

where now the $\mathrm{E}^{\mathrm{S}}(\mathrm{w})$ function may well have zero or negligible slope. The production function is written:

$$
y=f(E) \text {. }
$$

The aggregate supply function defined by (15) and (6'),

$$
y=f\left(\min \left(E^{d}, E^{s}\right)\right)=y(N, w) \text {, }
$$

depends on which regime we are in. Specifically:

$$
\begin{aligned}
& y_{N}=E_{N}^{d_{N}}<0 \text { if } E^{d}<E^{S} \\
& =0 \quad \text { if } E^{\varsigma}<E^{d} \text {, } \\
& y_{W}=E_{w}^{d}<O \text { if } E^{d}<E^{s} \\
& =E_{W}^{S} f^{\prime}>0 \text { if } E^{S}<E^{d} .
\end{aligned}
$$

I also require a specification of wage dynamics, for which the following phillips curve model seems appropriate:

$$
\dot{W} / W=\pi+\gamma\left(E^{d}(w, N)-E^{S}(w)\right) \text {, }
$$

where $W$ is the money wage and $\gamma$ is a positive constant. Since I am restricting my attention to cases where $\pi$ is zero, this reduces to:

$$
\dot{w} / \bar{w}=\gamma\left(E^{d}-E^{s}\right),
$$

so that by subtracting $\dot{\mathrm{P}} / \mathrm{P}$ (using equation (11) with $\pi=0$ ) I arrive at a law of motion for the real wage:

$$
\dot{w} / w=\gamma\left(E^{d}(w, N)-E^{3}(w)\right)+\theta\left(N-N^{*}\right) \text {. }
$$

Along with equations ( 9 ) and (12) (for $\dot{N}$ and $\dot{m}$ ) of the clearing model, this constitutes the dynamics of the disequilibrium modeI.

The aggregate demand curve $(4)$ is exactly the same as in the clearing model, except that expected inflation is now constrajned to be zero. So the new solution function for $x$ : 


$$
\mathrm{x}=\mathrm{x}(\mathrm{N}, \mathrm{m}, \mathrm{w} ; \mathrm{g})
$$

is defined by:

$$
x(N, m, w ; g)=D(y(N, w) ; m, o, g)
$$

so that

$$
\begin{aligned}
& x_{N}=D_{Y} y_{N} \\
& x_{m}=D_{m} \\
& x_{W}=D_{y} y_{w} \\
& x_{g}=1 .
\end{aligned}
$$

This completes the specification of the non-clearing version of the model.

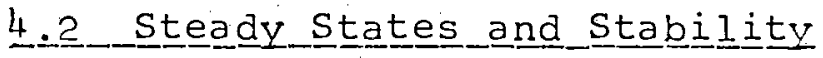

What can we hope to learn from such a complicated model? First consider the steady state properties, which hold also in a more elaborate version of the model in which the adaptive inflationary expectations equation is maintained. As before, (10) implies that actual and expected inflation are equal, so that (II) implies that $\mathbb{N}=\mathbb{N}^{*}$. Then (12) implies that the equilibrium inflation rate is zero, and (18) implies that the labor market clears: $E^{d}\left(w, \mathbb{N}^{*}\right)=E^{S}(w)$. This equation pins down the equilibrium real wage; and hence the equilibrium values of $E, y$ and $x$, and allows no effect of either policy variable. The rest of the model (the full-employment Is-LM model) determines $r$ and $P$ as usual. Nothing very interesting here.

Of greater interest are the short-run responses of the variables to shocks. But before enquiring into these dynamics, it is important to know what parameter configurations render the non-clearing model. stable. The appendix shows that stability requires:

$$
0+\gamma \mathrm{E}_{\mathrm{N}}^{\mathrm{a}}<0
$$

which turns out to be critical to the cyclical response of real wages (see below). Hereafter I assume that (20) holds. Notice once again that this is an assumption that inventory effects on production are "strong enough."

4.3 Shhort_Run Dynanic ic Responses

Given an initial state of disequilibrium in the labor market, what are the effects of stabilization policy on employment and wages? The answer is obtained with the aid of figure 4 , Here $\mathrm{IS}^{\mathrm{S}}(\mathrm{w})$ is the lobor 
supply schedule, $E^{d}\left(w, N_{0}\right)$ is the labor demand schedule, and the initial real wage is assumed to be $w_{0^{-}}-$which leads to an excess supply of labor (see point $B$ ). The initial level of inventories, $\mathrm{N}_{O}$, could be above or below the optimal level, $\mathrm{N}^{*}$, and, depending on where we are in the cycle, $N$ could be either rising or falling. Irrespective of this, any increase in $g$ or $M$ will reduce $\hat{N}(t)$ for some interval of time, thus pushing $N$ down rellattive $\underline{\text { e }}$ to would have been. This is shown in Figure 4 by an upward shift in the demand function for labor from $E^{d}\left(w, N_{0}\right)$ to $E^{d}\left(w, N_{1}\right)$ (where $N_{1}<N_{0}$ ). - That the expansionary stabilization policy has two distinct effects on the ratte of change of real wages can be seen from equation (18). First, a lower $N$ raises $\dot{w} / w$ through the first term in (18). This represents a "tightening" of the labor market (see equation (17)). Second, a lower $N$ reduces $w / w$ through the second term in $(18)$. This happens because smaller inventories lead to faster increases in product prices (see equation (11)).

But which effects dominates? The answer follows from stability condition (20): in a stable system, the first effect must be stronger so a reduction in inventories leads to an acceleration in real wage growth in the short run. Figure 4 shows what happens to output. In the absence of policy, wages would have fallen to some level like $w_{1}$ at time $t_{1}$, and the position of the economy would have been point $C$, with employment $B_{1}$. Expansionary policy pushes the labox demand curve outward and retards the fall in wages. Wages fall only to $w_{1}$, and the position of the economy at time $t_{1}$ is point $D$ instead. The effect of policy on employment is, therefore, $E_{i} . E_{3}$, a positive number.

Notice that this model. generates an unambiguous predicitor about the short-run behavior of real wages, whereas in the BARRO-GROSSMAN analys is "it all depends" on whether prices or money wages react more expeditiously to disequilibrium. How have I avoided this indeterminacy and obtained an answer that does not depend on relative adjustment speeds? The answer is that the short-run movement of $w$ doeㅗ still depend on relative adjustment speeds, but stability condition (20) places a quantitative restriction on $\gamma$ and $\theta$ that enables 


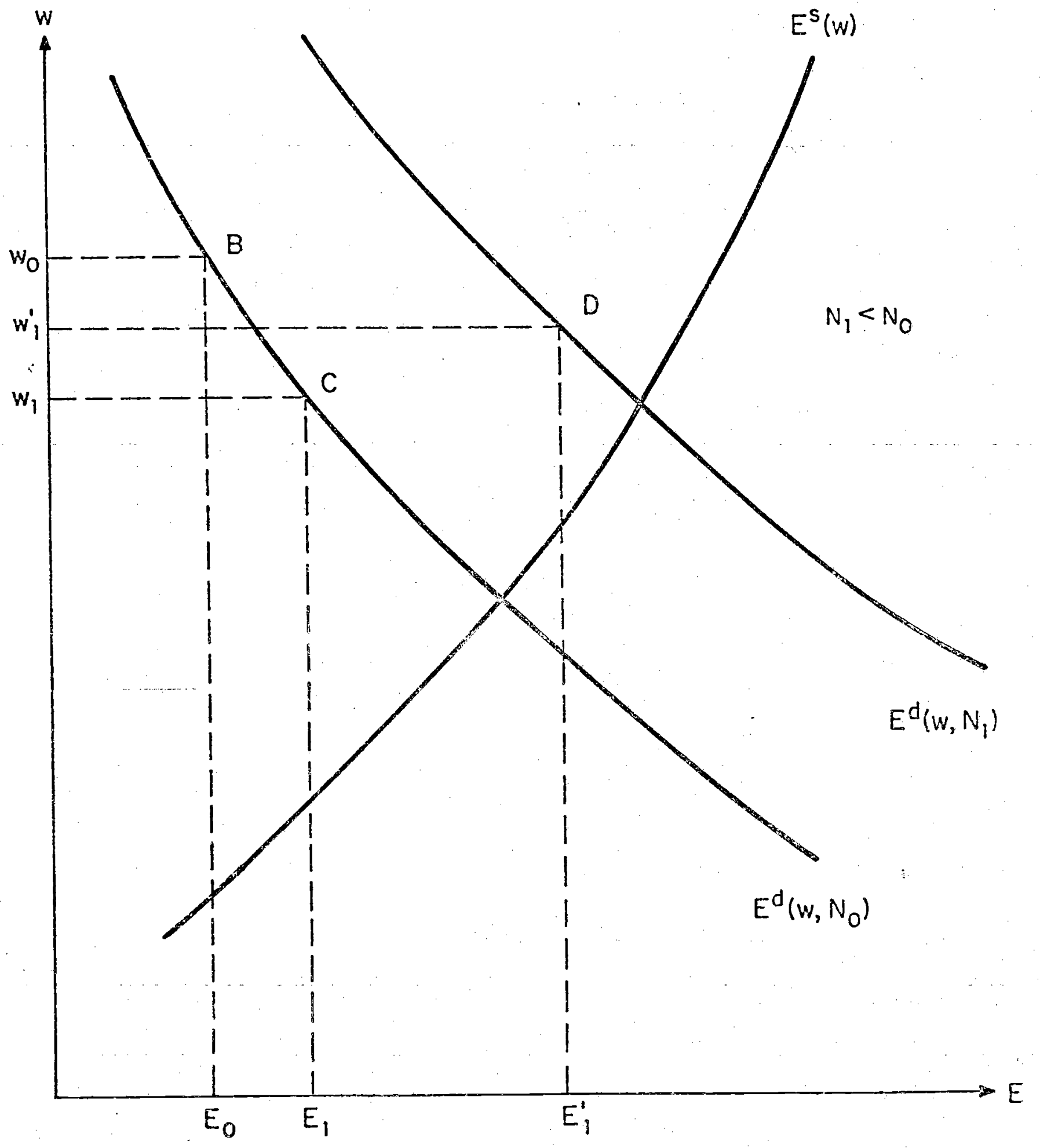

Figure 4 
me to determine the sign $\dot{w}$ in the short-run. 20

Precisely analogous arguments can be used to show that employment and wages also rise when expansionary policies are applied under conditions of excess demand or of equilibrium. In each case, a stimulus to aggregate demand leads to an interval of time in which $\dot{N}$ is more neqative and $\dot{w} / w$ is more positive than it otherwise would have been. It can also be shown that output rises. Thus, just as in the clearing model, we conclude that real wages move procyclically. In addition, the present model implies a certain symetry where BARRO and GROSSMAN found asymmetry. More demand always leads to higher real wages and higher output in the very short run, and less demand leads to lower real wages and output. However, the symmetry is only quali itativive, not qua $\underline{\text { nt}}$ itaㅡ는. Because employment is demand-determined when there is excess supply, and supply-determined when there is excess demand, the responses of $w$ and $y$ to policy will surely differ in the two cases. In particular, we expect a much greater output response when there is excess supply of labor than we do when there is excess demand.

V._-_S Limmary

1. In a sense, the most basic conclusion of this paper may be that inventories really do matter in macroeconomic theory. The presence of storable output apparently can change even basic quali litaa.tive aspects of the behavior of macro models.

2. While the great variety of motives for holding inventories suggest a number of ways in which inventories might enter the macro model, many of them seem to suggest that output inventories should have. a negative effect on the demand for labor (or supply of output). Input inventories ramain an unexplored territory worthy of study.

3. While inventories play an important stabilizing role at the level of the firm, they tend to be destabilizing at the macro leve the sense that models with inventories are stable in a smaller subset of the parameter space than are models without inventories. This message dates back to Metzler (19:1); but the mechanisms and precise stability conditions are quite different in this model than they were in Metzler's. In general, stability requires not only that inventories have a negative effect on the demand for labor, but that this effect be "large enough." 
4. Because of inventory changes, short run fluctuations in aggregate demand have quicker and more dramatic effects on final sales than they do on production.

5. Real wages respond positively to positive shocks to aggregate demand, because inventory changes shift the demand curve for labor. In the case of a nonclearing labor market, this conclusion hinges upon a stability condition which again states that the inventory-induced shifts in labor demand are "large enough." As was pointed out in the introduction, this conclusion is the reverse of that reached by standard Keynesian analysis, and also by search-theoretic models. This is because those models consider a cyclically-sensitive labor supply curve shifting along a labor demand curve, while the model developed here has a cyclically sensitive labor demand curve shifting along a fixed labor supply curve. If both curves were allowed to shift simultaneously, demand stimuli would have ambiguous effects on real wages, Which effect dominates in practice is an empirical issue.

It is probably apparent that other mechanisus that shift the demand for labor during the business cycle could be introduced. 21 But putting inventories into the labor demand function is not a contrivance designed to make real wages move procyclically. Quite the contrary, it seems to be an almost inescapable conclusion on both microeconomic and macroeconomic grounds. From the micro perspective, given any kind of imperfection in the market that allows the shadow value of inventories to depart from the market price, optimizing behavior seems to dictate that employment be a decreasing function of inventories in a wide variety of models.22 From the macro perspective, it is hard to make sense of either the Keynesian cross or the Is curve without explicit consideration of the firm's reaction to inventory imbalances. 25 6. Finally, the Keyriesian model with inventories predicts that real output will move in the same direction as aggregate demand, regardless of whether the demand shock is administered from an initial position of equilibrium, excess supply, or excess demand. In this respect, it contrasts shorply with the implications of the BARRO-GROSSMAN mode 1 . 


\section{A._-_Stabilility_Analysis in the clearing Model}

Using the solution functions given in the text for $y$ and $x$, the dynamic system can be written as a system of three differential equations, the first two of which are nonlinear:

$$
\begin{aligned}
& \dot{N}=Y(N)-X(N, m, \pi ; g) \\
& \dot{m}=-\theta m\left(N^{*}-N\right)-\pi m \\
& \dot{\pi}=\beta \theta\left(N^{*}-N\right) .
\end{aligned}
$$

Linearizing the nonlinear equations around equilibrium ( $\mathrm{x}=\mathrm{y}$, $\mathrm{N}^{*}=\mathrm{N}, \pi=\dot{\mathrm{p}} / \mathrm{P}=0$ ) gives the following stability matrix:

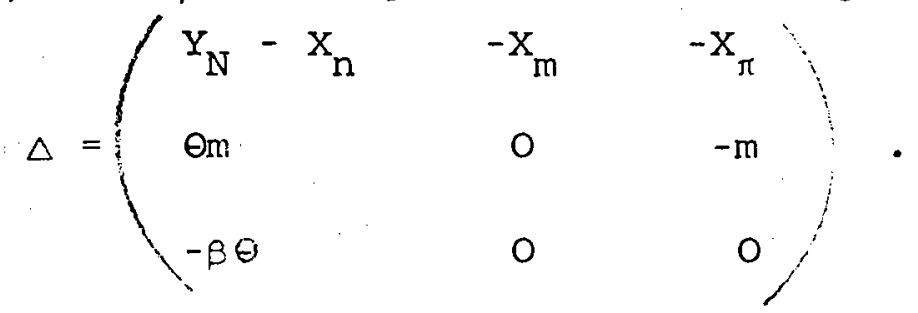

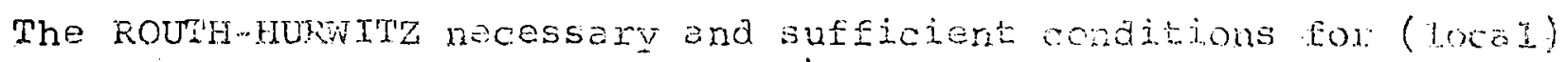
stability in this case are that: ${ }^{24}$

(i) $\operatorname{tr}(\Delta)<0$

(ii) $\operatorname{det}(\Delta)<0$

The trace,

(iii) $-\theta\left(Y_{N}-X_{N}\right)\left[m x_{m}-\beta X_{\pi}\right]-\beta \theta m x_{m}>0$.

$$
\operatorname{tr}=\mathrm{Y}_{\mathrm{N}}-\mathrm{X}_{\mathrm{N}}=\left(1-\mathrm{D}_{\mathrm{Y}}\right) \mathrm{Y}_{\mathrm{N}}
$$

is negative so long as $D_{Y}$ (the marginal propensity to spend) is less than unity and $Y_{N}$ is negative. The determinant is simply - $\theta \theta_{n} x_{m}$, which is negative so long as rising real balances otimulate demand. unly condition (iij) requires furbher anolysis, and by using the definitions of $x_{m}$ and $x_{\pi}$ it can be expressed as equation (14) in the text.

\section{B. Stabbility Analysis in the Noncleaxing Model.}

In the nonclearing model, $w$ replaces $\pi$ as the third state variable. Also, the solution functions differ and depend on whether there is excess supply or excess demand (see the text). The dynamic system is: 


$$
\begin{aligned}
& \dot{\mathrm{N}}=\mathrm{y}(\mathrm{N}, \mathrm{w})-\mathrm{x}(\mathrm{N}, \mathrm{m}, \mathrm{w} ; \mathrm{g}) \\
& \dot{\mathrm{m}}=\theta_{\mathrm{m}}\left(\mathrm{N}-\mathrm{N}^{*}\right) \\
& \dot{w}=\gamma_{w}\left(\mathrm{E}^{\mathrm{d}}(\mathrm{w}, \mathrm{N})-\mathrm{E}^{\mathrm{S}}(\mathrm{w})\right)+\theta w\left(N-\mathrm{N}^{*}\right) .
\end{aligned}
$$

Linearizing it around equilibrium $\left(N=N^{*}, E^{d}=E^{S}\right)$ gives the stability matrix:

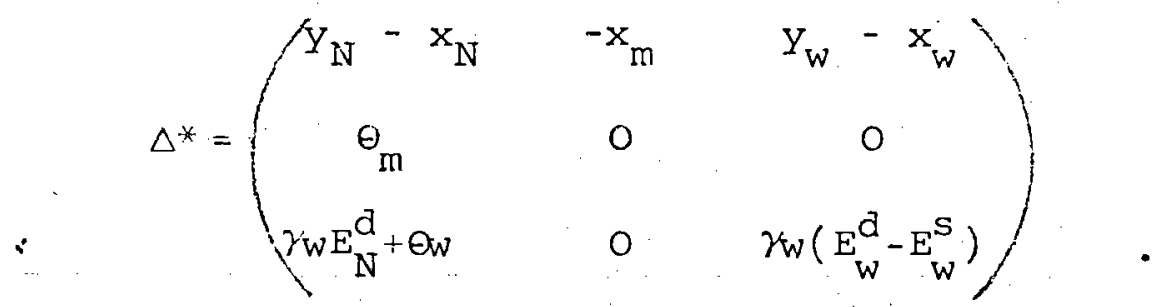

The three ROUTH-HURWITZ necessary and sufficient conditions for local stability are:

$$
\begin{aligned}
& \text { (i*) } \operatorname{tr}\left(\Delta^{*}\right)=y_{N}-x_{N}+\gamma_{w}\left(E_{w}^{d}-E_{w}^{s}\right)<0 \\
& \text { (ii*) } \operatorname{det}\left(\Delta^{*}\right)=\operatorname{enx}_{m} \gamma w_{w}\left(E_{w}^{d}-E_{w}^{s}\right)<0
\end{aligned}
$$

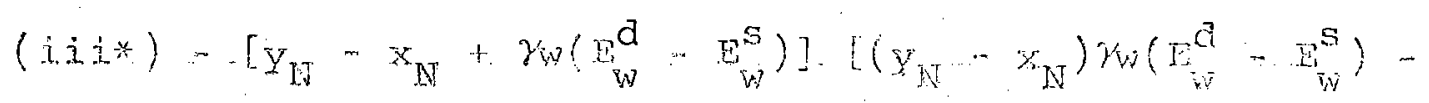

$$
\begin{aligned}
& \left.-\left(y_{w}-x_{w}\right)\left(\theta_{w}+\gamma_{w} E_{N}^{d}\right)\right]-\left(y_{N}-x_{N}\right) x_{m} \theta m>0
\end{aligned}
$$

The first two are clearly satisfied whether the systen has excess demand or excess supply in the labor market, but (iii*) looks different in the two cases. The excess demand cose is simpler since here $Y_{N}=x_{N}=0, y_{W}-x_{W}=\left(1-D_{Y}\right)_{Y_{W}}>0$. The condition reduces to:

$$
\gamma_{w}\left(E_{w}^{d}-E_{w}^{s}\right)\left(y_{w}-x_{w}\right)\left(e_{w}+\gamma_{w} E_{N}^{d}\right)>0
$$

which is true if and only it:

(20) $\theta+\gamma \mathrm{E}_{\mathrm{N}}^{\mathrm{d}}<0$,

as stated in the text.

When there is excess supply in the labor market, $y_{N}-x_{N}=\left(1-D_{Y}\right)$. $y_{N}<0$ and $\left(y_{W}-x_{w}\right)=\left(1-D_{y}\right) y_{w}<0$, so a sufficient (though not necessary) condition for stability is:

$$
Y_{N} \gamma_{w}\left(E_{w}^{d}-E_{w}^{s}\right)>y_{w}\left(\theta+\gamma E_{N}^{d}\right) \text {. }
$$

But, looking back at (16), we see that $y_{N} E_{W}^{d}=y_{W} E_{N}^{d}$, so this reduces to:

$$
-\gamma_{N}^{d} E^{\prime} E_{W}^{s}>\theta f^{\prime} E_{W}^{d},
$$

which is true if (20) holds. 
1. Among the many examples that could be cited, see Samuelson ( 1976), pp. 22.2-225.

2. For example, Branson's (1979) popular text never mentions inventories once it gets past the rehash of freshman-level materials. Even Lovell (1975), himself an inventory expert, fails to give inventories any role in the elaborated IS-LM model. 3. A notable exception is Maccini (1976).

4. Barro and Grossman note this quite explicitly. See, for example $(1971$, p. 85n) or $(1976$, p. $41 n)$.

5. The statement applies to the U.S. and other advanced industrial nations. The Barro-Grossman excess demand scenario may be applicable to centrally planned economies where consumer goods are in chronically short supply. (On this, see Howard (1976).) The preceaing discussion is in the spirit of Leijonhufvud (1973).

6. This has important implications for econonetric specification of macro models. The Barro-grossman model, with its many cases, woula require a complex "switching regressionsi appoach of the sort aiscussed e.g., by Goldfeld and quandt (1976). The model. that I shall present has no switches of regimes.

7. For a version of this scenario consistent with rational. expectations, see Fischer (197?).

8. Alternatively, a falling supply price (e.g, quantity discounts) will give the firm an incentive to bunch its input purchases.

9. For a full discussion of when $\lambda$ can or cannot differ from the market price, see Blinder (1978). Suffice it to say that some deviation from perfect markets-..for example, some monopoly power-.. is reciuired.

10. A notable exception is Eair's (1976) model. His equation for output (equation (10) on page 49) can be written (if I ignore lags and dumiy variables):

$$
y=\text { constant }+1.2 \mathrm{x}-.236 \mathrm{~N} \text {, }
$$

which certainly shows a rather strong negative effect of inventories on output. 
11. See Ando and Shel1 (1975).

12. Given' (5), it does not matter whether $I$ put $E^{d}$ or $E^{s}$ into the production function.

13. The expectational mechonism is not critical to any results in this paper, and is needed only to connect nominal and real interest rates. For a model with a similar, though somewhat simpler, structure that includes explicit stochastic terms and utilizes rational expectations, see Blinder and Fischer (1979).

14. Feldstein and Auerbach (1976) have suggested that, as an empirical

- matter, changes in $N^{*}$ proceed very sluggishly in U.S. durable manufacturing industry.

15. Had I modelled monetary policy as fixing the growth rate, $\dot{M} / \mathrm{M}$, rather than the level, $M$, inflation would be possible in

equilibrium. However, my choice seems the more natural one in the context of an ultimately static model. The whole model can be transformed into a growth model with relatively little difficulty.

16. This conclusion is the only one in the papex that depends on the assumption of adaptive expectations. Because of this, the rate of change of the rate of inflation is:

$$
\begin{aligned}
\frac{d}{d \bar{t}}\left(\frac{\dot{P}}{\mathrm{p}}\right) & =\dot{\pi}-\dot{\theta N} \\
& =\theta\left(\frac{\dot{p}}{p}-\pi\right)>0 \text { at the point where } \dot{N}=0 .
\end{aligned}
$$

17. In the mode1, they reach this peak in the "fixst instant, "but if. lags in the consumption and investment function were allowed, the "multiplier" would take some time.

18. point $E$ is where the slope of the trajectory, $\dot{x} / \dot{y}$, is equal to unity, for at this point $\dot{N}=\dot{x}-\dot{y}=0$.

19. Assuming ( 14$)$, of course, does not guarantee monotonic convergence. I depicted this case in Figure 2 , but nothing of consequence hinges on it; overshooting is possible.

20. An open question is whether the effect on $\dot{w}$ could be signed by $a$ similar stability analysis of the Barro-Grossman model.

21. For example, the stock of capital or the intensity of its utilization might affect labor demand.

22. On this, see Blinder (1978) and Blinder and Fischer (1979).

23. On this, see Blinder (1977).

24. See, for example, Gandolfo (1971), p. 241. 
Ando, Albert and Karl Shell, "Demand for Money in a General Portfolio Model in the Presence of an Asset that Dominates Money," in

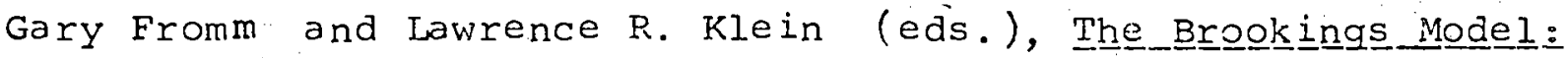

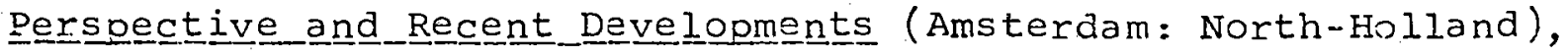
1975 .

Baxro, Robert J. and Herschel I. Grossman, "A General Disequilibrium

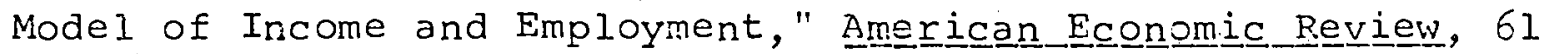

- (March 1971), pp. 82-93. , Money, Employment and Inflatation (Cambridge, U.K.: Cambridge University Press), 1976.

Blinder, Alan S., "A Difficulty with Keynesian Models of Aggregate

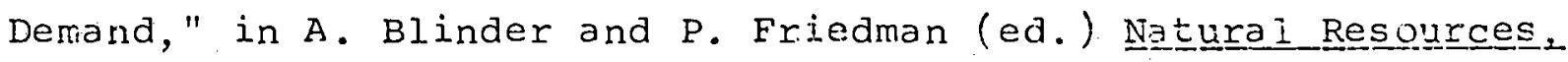

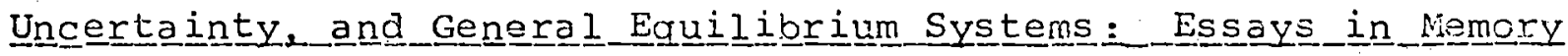
of Rafael Lusky (Academic Press: New York), 1977.

$$
\text { "Inventories anc the Demand for Izbor, "mimeo, }
$$

Princetor University, April 1978.

Blinder, Alan S. and Stanley Fischer, "Inventories, Rational

Expectations, and the Business Cycle," National Bureau of Economic Research Working Paper No. 381, August 1979.

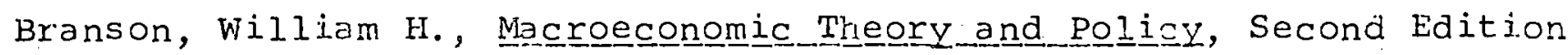

(New York: Harper and Row), 1979.

Cagan, Philip, "The Monetary Dynamics of Hyperinflation," in M. Friedman

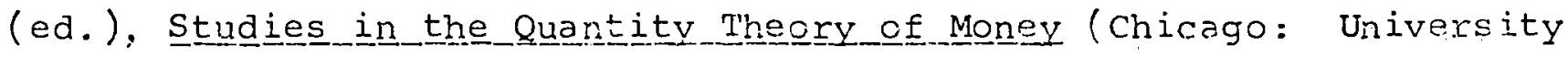
of (hicago Press), 1956.

Fair, Ray c., A Model of Macroeconomic Activity, Volume_e : The Empirical Mode1 (Cambridge, Massachusetts : Ballinger), 1976.

Feldstein, Martin S. and Alan Auerbach, "Inventory Behavior in Durable

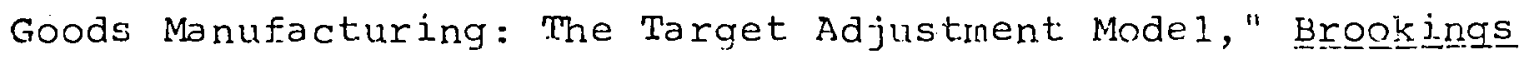
Papers on Economic Activity, $2: 1976$, pp. $351-396$.

Fischer, Stanley, "Long-Term Contracts, Rational Expectations,

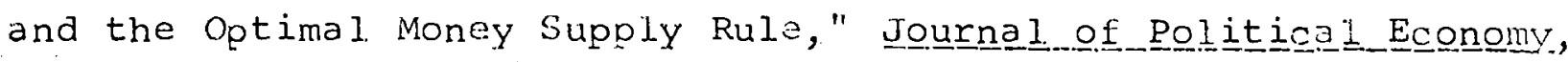
February 1977, pp. 191-205.

Gandolfo, Giancaxlo, Mathematicical_Methods and Models in Economic Dynamics (Amsterdam: North-Holland), 1971. 
Goldfeld, Stephen M. and Richard E. Quandt, "Techniques for Estimating Switching Regressions," in S. M. Goldfeld and R.E. Quandt (eds.),

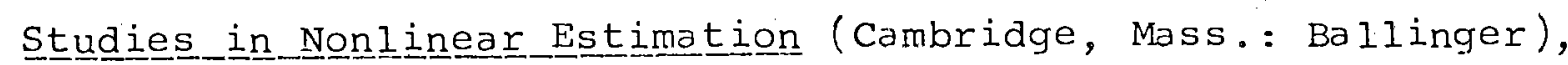
1976.

Gordon, Robert J., "The Impact of Aggregate Demand on Prices," Brookings papers on Ecoㅡomic Activity, $3:$ 1975, pp. 613-644. Holt, Charles C., Franco Modigliani, John F. Muth and Herbert A. Simon, Planning produchetion, Inventories and Work Force. (Englewood Cliffs, N.J.: Prentice-Ha11), 1960. :Howard, David H., "The Disequilibrium Model in a Controlled Economy: An Empirical Test of the Barro-Grossman Model, "American Econon Review, 66 (December 1976), pp. 871-879.

Leijonhufvud, Axel, "Effective Demand Failures," The _ Swed 으 Economics, 75 , March 1973, pp. $27-48$.

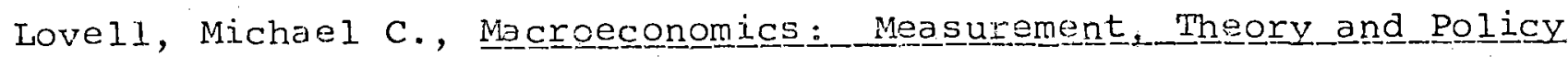

(New York: John Wiley), 1975.

Maccini, Louis J., "An Aggxegate Dynamic Model of Short-Run Price and Outout Behavior," Quarterly Journal of Economics, 90, 1976, pp. $277-196$. , "An Empirical Model of Price and Output Behavior," EconomicIㅡㅁuiry, 15 (October 1977), pp. 493-51.2.

Metzler, Lloyd A., "The Nature and Stability of Inventory Cycles," Review of Economic Statistics, 23, 1941.

Mills, Edwin S., Price, Output and Inventontory Pollicy (New York: John Wiley), 1962 .

Samuelson, Paul A。, Economics, Tenth Edition (New York: McGraw Hill), .2976 . 